\title{
Funding row delays Brussels BSE research
}

Paris. A fierce row has broken out between officials of the European Commission in Brussels and the French government over the financing of a proposed increase of ECU50-million (US\$62.5-million) in the European Union's (EU) research effort into bovine spongiform encephalopathy (BSE) and Creutzfeldt-Jakob disease (CJD).

Research ministers of the EU member states last week approved the proposal for the new ECU50-million programme. But they failed to agree on a request from Edith Cresson, the EU's research commissioner, that the money should be taken not from existing EU research funds, but from the ECU200 million remaining in the commission's internal budget. As a result, a decision on how the programme will be financed will not be taken until the next meeting of research ministers on 5 December.

Cresson argued that extra money was needed because there was not enough

\section{Panel urges precautionary approach}

Paris. The UK government's optimism that bovine spongiform encephalopathy (BSE) will die out around the end of the decade (see Nature 383, 209; 1996) received a further blow last week. A panel of scientists set up by the European Commission to recommend priorities in research into transmissible spongiform encephalopathies warned that the risk that the disease would become endemic cannot be discounted, and that research is urgently needed to anticipate this possibility.

The panel, chaired by Charles Weissmann, from the Institute of Molecular Biology in Zurich, pointed out in its report to the commission that predictions that the disease will be eradicated are based on assumptions that might not "hold true", while the agent that causes the disease might mutate, or be transmitted in ways that are not yet known. As a result, it proposes a detailed programme of fundamental research into the transmissible spongiform encephalopathies.

Weissmann added that action should be taken as if transmission of the disease between cattle and humans "were true". The report calls for a review of the epidemiology of BSE, and of the infectivity of cattle tissues and the products in which they are used, arguing that the mouse assays used previously to evaluate infectivity "are very insensitive."

Continuing in the same precautionary vein, the report calls for the determination of "the contamination level of meat with brain/spinal cord after standard butchering procedures." Similarly, it calls for a review of maternal risk factors in the transmission of BSE in cattle, and the determination of the infectivity of "placenta, blood, colostrum, milk, and excrements of BSE cattle".

The report, which was discussed at a press conference in Brussels last week by Weissmann and Franz Fischler, the European Union's agriculture commissioner, also calls for a series of studies

\section{IMAGE UNAVAILABLE FOR COPYRIGHT REASONS}

Weissmann (right) and Fischler outline recommendations for research into BSE.

to assess the risk of BSE to humans.

Surveillance of BSE and CJD should be extended throughout Europe, according to the report, adding that CJD epidemiology should "monitor for linkage to consumption of cattle and sheep products". The panel's reference to sheep products will be enough to send shudders through the commission's agriculture directorate.

Indeed, Weissmann's report makes explicit the fact that sheep may also pose a risk to human health. "It is possible that BSE originated as a (rare) spontaneous event in cattle and that the BSE agent is different from the scrapie agent. If so, then BSE may have been transmitted to sheep via bone and meat meal from cattle and BSE infected sheep could transmit the agent to man." As a result, it recommends EU-wide surveillance of scrapie, and studies to identify the infectious agent in recent UK cases of "sheep 'scrapie"”.

Again assuming the worst-case scenario, the report calls for an accurate assessment of any past risk to which humans were exposed, including an analysis of the use of offal in various foods, and the consumption of these by various "age groups and socio-economic criteria." A diagnostic test for CJD/BSE is a priority, it adds. money left in the commission's 1997 life sciences budget to cover the ECU50-million programme, according to her spokesman, Jean-Christophe Filori. He says that this proposal was opposed only by "France, France and France", in the person of François d'Aubert, the French secretary of state for research.

The result, claims Filori, will be an unnecessary delay in the launch of the programme. "It's absolutely ludicrous that at a time when ministers are writing cheques of billions of Ecus to support the beef market [following the BSE crisis], they are being petty about ECU50 million for research."

But his claims are strongly denied by the French ministry of research, which accuses the commission of "disinformation". A spokesperson for d'Aubert says that the proposal agreed last week for an increase in the EU's research effort in BSE/CJD was itself originally put forward by d'Aubert in a letter to Cresson in June, and that d'Aubert later specifically asked the EU's Irish presidency to have it put on the agenda of the meeting of research ministers. "We are very pleased that the meeting approved the French proposal," he says.

The spokesperson also contests Cresson's claim that the research budget does not have enough funds left to cover the costs of the proposed programme. He says that d'Aubert in fact favoured taking the money from the research budget, because it would speed up the process. The transfer of money between EU budgets involves the "most complicated and drawn out budgetary procedures the commission has", he says, arguing that in contrast, diverting money from the research budget to the proposed BSE/CJD programme "could be done in a matter of days", as it would only require a vote by a programme committee.

Moreover, d'Aubert's spokesperson claims that all the member states - and not just France - opposed Cresson's proposal for funding of the programme. He alleges that the research directorate is stirring up trouble to score political points in its bid to obtain an injection of extra money for the agreed ECU13.1-billion EU research budget. Indeed, Cresson has hoped to obtain an increase of ECU700 million in the budget. But, ironically, the commission's overall budget has become strained by the BSE crisis, and a meeting of EU finance ministers this week was expected to reject her request.

A spokeswoman for the UK Department of Trade and Industry agrees that France was not alone in refusing to agree to Cresson's funding proposal last week. Britain's view was that the commission "needed to verify how much it had in its research coffers" before any decision could be made at the next meeting of research ministers in December, she says.

Declan Butler 